\section{Histologically proved basal cell carcinomas in identical twins}

Basal cell carcinoma (rodent ulcer) is the commonest skin malignancy occurring in white races, regardless of climatic influence. Although sunlight and ionising radiation are felt to be aetiologically important, Urbach $^{1}$ showed that a third of basal cell carcinomas appear on areas normally slightly exposed to ultraviolet radiation, suggesting that other factors played an appreciable part. Basal cell carcinomas may develop in naevus verrucosus, vaccination sites, or old burn scars; and arsenical tonics taken years previously may predispose to their development. Sanderson ${ }^{2}$ felt, however, that basal cell carcinomas may have a familial incidence unrelated to the aforementioned factors.

Gorlin's syndrome, inherited by an autosomal dominant gene, manifests as multiple basal cell carcinomas, usually present at adolescence and variably associated with jaw cysts; rib and vertebral abnormalities; palmoplantar pits; and eye and neurological disorders. Basal cell carcinoma can occur in xeroderma pigmentosum, which is inherited as an autosomal recessive. According to Riccardi and Cleaver ${ }^{3}$ at times an increased familial occurrence of malignancy does not conform to Mendelian patterns of inheritance and this sometimes applies to familial basal cell carcinomas.

\section{Case reports}

A 65 -year-old spinster presented with a slowly enlarging abnormal patch of skin on her back which had been present for two and a half years. There was minimal irritation and as she had suffered from mild eczema she mistook this for the same. In the centre of her upper back she had an erythematous, slightly crusted lesion with several other islands of abnormal tissue, suggesting the diagnosis of multicentric superficial basal cell carcinoma. Histological examination of a biopsy specimen showed four foci of superficial basal cell carcinoma.

Inquiry into her family history showed that her identical twin spinster sister had a similar patch on her back (figure). When the latter was seen there was no doubt that the twins were identical, and the asymptomatic lesion on the second twin's back had been present for just over two years. Just to the left of the mid line of her upper back were erythematous lesions with slightly rolled translucent margins, suggestive of multiple islands of basal cell carcinoma and confirmed on histological examination.

Both women had lived together all their lives in Eastbourne and may have had arsenical salts as they had received tonics as children and this could have played a part in the development of their lesions.

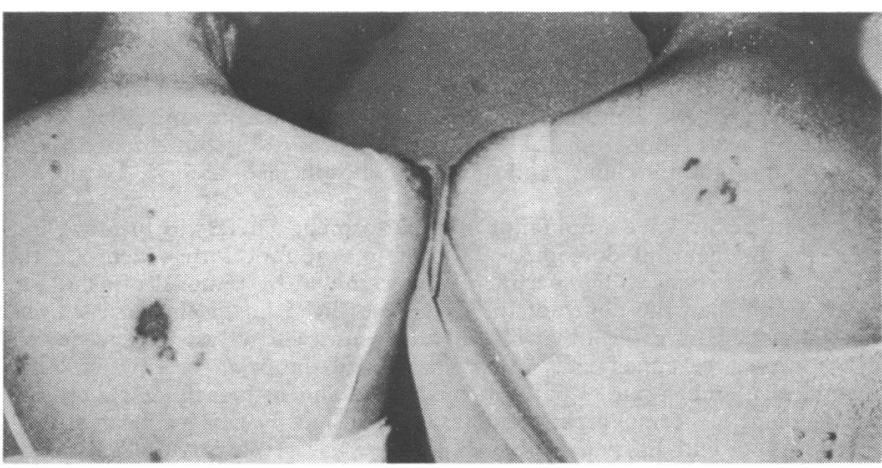

Erythematous, slightly crusted lesions with areas of abnormal tissue, suggesting multicentric superficial basal cell carcinoma, on the backs of twin sisters.

\section{Comment}

Urbach $^{1}$ reported that in one study $88 \%$ of basal cell carcinomas occurred on the head and neck. Certainly in Britain the back is an uncommon site, especially in women, except where there has been radiotherapy to the back, and neither twin had received this.

In 1956 Oettle $^{4}$ reported basal cell carcinoma in the right mastoid region in monozygotic male twins, but the lesions had developed three years apart. The results of histological examination were unavailable on the first twin who developed the lesion, but their elder brother had developed a basal cell carcinoma on the forehead at the age of 36 .

The fact that the twin sisters developed a basal cell carcinoma at virtually the same time, in an almost identical atypical site, and with an unusual morphology suggests that they had inherited a localised susceptibility to the development of basal cell carcinoma. They had no other manifestations of Gorlin's syndrome and had also not simply inherited a generalised increase in susceptibility to sunlight, such as occurs in xeroderma pigmentosum, for evidence of other basal cell tumours was lacking. The identical twin sisters closely match the male identical twins described by Oettle ${ }^{4}$ in their development of basal cell carcinoma and possibly they inherited a biochemical defect underlying the development of the carcinoma, although the precise localisation effect is bizarre.

1 Urbach, F, The Biologic Effects of Ultraviolet Radiation, p 644. Oxford, Pergamon Press, 1969.

${ }^{2}$ Sanderson, K V, in Textbook of Dermatology, ed A Rook et al. Oxford, Blackwell Scientific Publications, 1972.

${ }^{3}$ Riccardi, V M, and Cleaver, J E, in Skin, Heredity and Malignant Neoplasms, ed H T Lynch. New York, Medical Examination Publishing Co, 1972.

4 Oettle, A G, Archives of Dermatology, 1956, 74, 167.

(Accepted 30 March 1978)

District General Hospital, Eastbourne, East Sussex BN21 2UD

KEITH LIDDELL, MB, MRCP, consultant dermatologist

\section{Repetitive cardiac arrest from electromechanical dissociation}

Abrupt loss of circulation without disturbance of electrical rhythm of the heart (electromechanical dissociation) is sometimes seen in a coronary care unit. One well-recognised cause is rupture of the ventricle.

Our case seems unique in that in 16 days after inferior myocardial infarction numerous episodes occurred in which the circulation stopped, the patient lost consciousness, but the electrocardiogram did not alter. In many episodes the circulation spontaneously recovered.

\section{Case report}

A 50-year-old man was admitted with severe central chest pain. The electrocardiogram confirmed recent inferior myocardial infarction. He made normal progress but on the tenth day, in a medical ward, he was found unconscious and pulseless. A nurse brought the portable defibrillator to him, considered that ventricular fibrillation was present, and gave two DC shocks of 100 joules. The pulse returned and an electrocardiogram showed sinus rhythm. Oral mexiletine, $100 \mathrm{mg}$ three times daily, was given as prophylactic antiarrhythmic treatment. Three days later, while the electrocardiogram was still being monitored, he developed ventricular tachycardia and within a minute ventricular fibrillation. He was defibrillated and sinus rhythm restored. During the next hour he had about ten episodes of clinical cardiac arrest, in which consciousness was lost, the pulse became impalpable, and the heart sounds disappeared. Each attack lasted about three minutes, and during two attacks he was intubated and ventilated by an Ambubag. On each occasion he recovered consciousness spontaneously. There was no chest pain. The monitoring electrocardiogram showed sinus rhythm for the whole of this time.

No further episodes of arrhythmia or loss of consciousness occurred for a full 24 hours. Then a further series of attacks occurred. He was seen to develop ventricular tachycardia and after a few moments lost consciousness. A DC shock was given (100 joules) and the arrhythmia terminated. Over the next hour we could document the nature of the circulatory disturbance several times. At intervals the heart sounds began to diminish in intensity, and the blood pressure steadily to fall to about $70 \mathrm{~mm} \mathrm{Hg}$ systolic. $\mathrm{He}$ then would lose consciousness and the circulation cease altogether. Sinus rhythm was maintained, and the electrocardiographic complexes were unchanged. In a fairly brief period the heart sounds suddenly returned, and the patient made an apparently complete recovery to normal levels of blood pressure. A diagnostic aspiration of the pericardium was performed to exclude the possibility of a steady leak of blood from the injured ventricle. No fluid was present. An electrocardiogram showed no evidence of extension of the original infarction. No further attacks developed for about a further six hours, but he then had a succession of attacks of ventricular tachycardia and ventricular fibrillation, and died.

The results of the relevant laboratory investigations are shown in the 
table for aspartate transaminase and hydroxybutyrate dehydrogenase. The blood urea concentration was $3.6 \mathrm{mmol} / \mathrm{l}$; serum concentrations of potassium were between 3.6 and $4.4 \mathrm{mmol} / 1$, magnesium $0.75 \mathrm{mmol} / \mathrm{l}$, and calcium $2.65 \mathrm{mmol} / \mathrm{l}$. At necropsy there was an extensive inferior myocardial infarction. The macroscopic changes were compatible with the infarct having occurred two weeks previously. There was no evidence of perforation of the ventricular wall or recent extension of infarction.

Cardiac enzyme concentrations $(I U / l)$

\begin{tabular}{l|c|c|c|c|c}
\hline Day & 1 & 2 & 11 & 12 & 15 \\
\hline AST & 14 & 242 & 46 & 25 & 59 \\
HBD & 447 & 519 & 414 & 282 & 216 \\
\hline
\end{tabular}

AST $=$ Aspartate transaminase $(\mathrm{SGOT}) . \mathrm{HBD}=$ Hydroxybutyrate dehydrogenase.

\section{Comment}

We were repeatedly able to witness the gradual development of complete electromechanical dissociation, which recovered spontaneously only to recur again after a short interval. In experimental preparations this phenomenon can be created by altering ionic concentrations in the perfusate. ${ }^{1}$ In this patient there was no disturbance of serum concentrations of potassium, calcium, or magnesium. The possibility that mexiletine may have been responsible must be considered. Cardiotoxicity may be associated with this drug but is usually seen with higher doses or administration by intravenous injection. ${ }^{2}$ Nevertheless, mexiletine is structurally related to lignocaine and both are classified as having a class I antiarrhythmic action. ${ }^{3}$ Oliver reported one patient with complete pump failure in the presence of normal sinus rhythm after intravenous lignocaine. ${ }^{4}$ In one review, of 663 patients admitted to a coronary care unit, 15 suffered instantaneous non-arrhythmic cardiac death. There were postmortem studies in seven of these and all had inferior myocardial infarction. Our case shows that electromechanical dissociation may be the cause of death in apparently otherwise uncomplicated inferior myocardial infarction.

Dr A J Marshall is supported by a research grant from the Bristol Health District.

${ }^{1}$ Kohn, R M, American fournal of Cardiology, 1963, 11, 483.

2 Talbot, R G, et al, Lancet, 1973, 2, 399.

${ }^{3}$ Singh, B N, and Vaughan Williams, E M, British fournal of Pharmacology, $1972,44,1$.

- Oliver, M F, Acute Myocardial Infarction, ed D G Julian and M F Oliver. Edinburgh, Livingstone, 1968.

${ }^{5}$ Raizes, G, Wagner, G S, and Hackel, O, American fournal of Cardiology, 1977, 39, 1.

(Accepted 30 March 1978)

Cardiac Department, Bristol Royal Infirmary, Bristol BS2 8HW A J MARSHALL, MD, MRCP, honorary senior medical registrar D W BARRITT, MD, FRCP, consultant physician

\section{Rectal carcinoma presenting as massive metastatic involvement of foot bones}

Although the overall incidence of metastatic involvement of bones in patients with malignant neoplasms is probably between 20 and $30 \%,{ }^{1}$ metastatic lesions of the bones of the feet are extremely rare. ${ }^{2}$ So far as we are aware this is the first report of massive involvement of the foot by metastatic carcinoma.

\section{Case report}

A 79-year-old woman presented with a four-month history of pain on the medial side of the right foot. On examination the only abnormality was

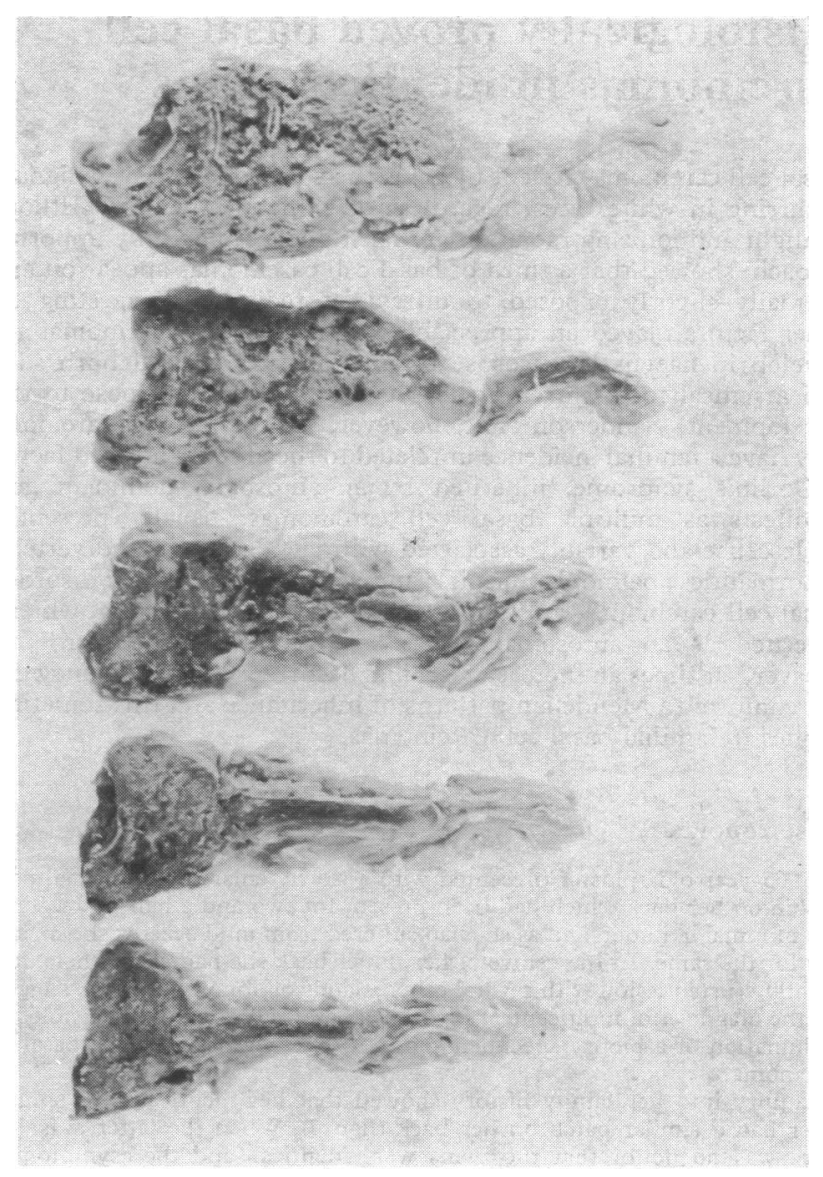

Slices of foot bones in lines of toes, showing extensive infiltration by grey-white tumour, with extension of tumour into joint spaces and adjacent soft tissue.

marked right hallux valgus and $x$-ray examination showed osteoporosis of the foot bones. Over the next eight months the pain in her foot worsened, with extreme pain on walking and increased swelling. Examination showed gross swelling of the dorsum, which was hot and pulsatile; mild hepatomegaly; a central abdominal mass; and a hard craggy mass felt per rectum. Radiographs now showed that the first, second, and third metatarsals and first cuneiform were eroded by neoplasm. Chest radiograph showed an enlarged heart but normal lungs. Erythrocyte sedimentation rate was $75 \mathrm{~mm}$ in first hour and alkaline phosphatase 256 IU/1 (normal 20-95 IU/1)

A right below-knee amputation was performed. There was firm swelling over the medial and dorsomedial aspects of the foot with oedema of the subcutaneous tissue. The specimen was examined by removal of skin, soft tissues, and then the bones of the foot were sliced in the line of each toe, after disarticulating the tibia, fibula, calcaneum, and talus. The navicular, cuboid, all three cuneiforms, the major part of the first, second, and third metatarsals, and proximal parts of the fourth and fifth metatarsals showed replacement of normal architecture and expansion by firm variegated greywhite tumour with haemorrhagic foci. There was variable cortical destruction and extension of tumour into joint spaces and adjacent soft tissue (figure). The extent of tumour and soft tissue involvement was clear on radiographs of the slices. In addition, the anterior surface of the calcaneum showed focal involvement with tumour, but the talus, tibia, fibula, and phalanges appeared to be unaffected. Microscopically, the affected bones were shown to be extensively infiltrated by acini of moderately well-differentiated, large, intestinal-type adenocarcinoma with areas of necrosis and new bone formation.

After operation the patient suffered from persistent diarrhoea, the only local symptom of her rectal carcinoma. It was considered that local intervention would not improve the prognosis. She was therefore treated symptomatically and the diarrhoea eventually resolved. Her stump healed satisfactorily and she could walk comfortably in a frame. She died at home five months after the amputation.

\section{Comment}

Osseous metastases of the foot are rare. Only 17 histologically proved cases have been reported. ${ }^{2}$ In 14 of these cases only one foot bone was affected. Colson and Willcox, ${ }^{3}$ however, reported a case 